\title{
Symmetrical Palladium (II) N,N,O,O-Schiff Base Complex: Efficient Catalyst for Heck and Suzuki Reactions
}

\author{
Wan Nazihah Wan Ibrahim ${ }^{1}$, Mustaffa Shamsuddin ${ }^{2}$ \\ ${ }^{1}$ Faculty of Applied Science, Universiti Teknologi MARA, Shah Alam, Malaysia \\ ${ }^{2}$ Faculty of Science, Universiti Teknologi Malaysia, Johor, Malaysia \\ Email: wannazihah@salam.uitm.edu.my
}

Received September 13, 2012; revised October 15, 2012; accepted October 26, 2012

\begin{abstract}
Palladium is arguably the most versatile and most widely applied catalytic metal in the field of fine chemicals due to its high selectivity and activity. Palladium catalyst offers an abundance of possibilities of carbon-carbon bond formation in organic synthesis. In this research, three different Schiff base ligands have been prepared by condensation reaction between appropriate aldehyde or ketone with amine namely 2,2-dimethyl-1,3-propanediamine in the molar ratio of 2:1. The corresponding palladium (II) Schiff base complexes were prepared through the reaction between the Schiff base ligand with palladium (II) acetate in a molar ratio 1:1. FTIR, ${ }^{1} \mathrm{H}-\mathrm{NMR}$ and ${ }^{13} \mathrm{C}-\mathrm{NMR}$ spectroscopic data revealed that the ligands are $\mathrm{N}, \mathrm{N}, \mathrm{O}, \mathrm{O}$-tetradentate coordinated to the $\mathrm{Pd}$ atom through both the azomethine $\mathrm{N}$ atoms and phenolic $\mathrm{O}$ atoms. From X-ray Crystallographic analysis, it showed that the complex exists as square planar geometry. The synthesized palladium (II) Schiff base complexes were then subjected in catalytic Heck and Suzuki reaction of iodobenzene.
\end{abstract}

Keywords: Palladium (II) Schiff Base Complex; Heck Reaction; Suzuki Reaction

\section{Introduction}

Tetradentate Schiff base is one of the most extensively studied ligands in coordination chemistry. They can coordinate with a large number of transition metals, as well as possessing numerous interesting properties to related catalysis and electrochemistry. One type of tetradentate Schiff base ligand is N,N,O,O-tetradentate donor set which possesses many advantages such as facile approach, relative tolerance, readily adjusted ancillary ligands, and tuneable steric and electronic coordination environments on the metal center [1,2]. Furthermore, they can be synthesized both simply and cheaply in a bulk amount which properties that become very important when industrial applications are being sought. Based on these unique properties, N,N,O,O-tetradentate Schiff base ligands and their transition metal complexes, as catalyst, have attracted significant attention being relevant for their application in agrochemical and radiopharmaceutical industries for cancer targeting, as model system for biological macromolecule [3]. In this research, we had prepared palladium (II) complexes coordinated with various types of Schiff base ligands. The synthesized palladium (II) Schiff base complexes were then subjected to Heck and Suzuki reactions in order to evaluate the activity of the catalyst.

\section{Experimental}

\subsection{Chemicals and Instrumentation}

All glass wares were dried overnight in oven. Commercial grade solvents were distilled according to normal procedures and dried over molecular sieves ( $4 \AA$ ) before used. All other chemicals were purchased from Aldrich, Merck or Fluka and were used without further purification and all reactions were conducted under inert condition. The melting point of the solid products was measured using Electrothermal Digital Melting Point Apparatus and was uncorrected. The CHN elemental analysis was determined using a Thermo Finnigan CE 125 CHN analyzer. Fourier Transform Infrared (FTIR) spectra of the synthesized samples were recorded on Shimadzu FTIR spectrometer in the range of $4000-400 \mathrm{~cm}^{-1}$ as potassium bromide ( $\mathrm{KBr}$ ) disc. The proton ${ }^{1} \mathrm{H}$ and carbon ${ }^{13} \mathrm{C}$ Nuclear Magnetic Resonance (NMR) spectra were recorded in $\mathrm{CDCl}_{3}$ or DMSO on a Bruker Avance 300 $\mathrm{MHz}$ and $400 \mathrm{MHz}$ spectrometer. The chemical shifts are reported in ppm relative to trimethylsilane (TMS). Single-crystal X-ray Crystallography was performed by using a Bruker SMART APEX2 CCD area detector diffractometer. Determination of products from the catalytic testing was carried out using gas chromatographic (GC) technique. Reaction mixture was analyzed by Agilent 
Technologies GC equipped with a $30 \mathrm{~m} \times 250 \mu \mathrm{m} \times 0.25$ $\mu \mathrm{m}$ nominal capillary column (ULTRA-1.0.05, 100\% dimethylpolysiloxane) using Flame Ionization Detection (FID).

\subsection{Catalyst Preparation and Characterization}

The stoichiometric amount of appropriate aldehyde or ketone derivatives $(10 \mathrm{mmol})$ was added dropwise to a 2,2-dimethyl-1,3-propanediamine solution $(0.51 \mathrm{~g} ; \rho=$ $0.851 ; 5 \mathrm{mmol} ; 0.6 \mathrm{~mL}$ ) in $10 \mathrm{~mL}$ dry ethanol. The mixture was refluxed $\left(78^{\circ} \mathrm{C}\right)$ under nitrogen gas atmosphere after which the solid product had formed. The solid products of Schiff base ligands were then separated by vacuum filtration, washed with cold ethanol and dried in vacuum desiccator $\left(25^{\circ} \mathrm{C}\right)$ for overnight. In order of complexation method, Schiff base ligand $(5 \mathrm{mmol})$ was dissolved in a $10 \mathrm{~mL}$ of dry acetonitrile. Palladium (II) acetate $(1.10 \mathrm{~g} ; 5 \mathrm{mmol})$ which was dissolved separately in a $10 \mathrm{~mL}$ of dry acetonitrile was then added dropwise into the flask containing the ligand solution. The mixture was stirred and refluxed $\left(90^{\circ} \mathrm{C}\right)$ under $\mathrm{N}_{2}$ gas atmosphere after which the solid product had formed. The product was then separated by vacuum filtration, washed with cold acetonitrile and dried in a vacuum desiccator $\left(25^{\circ} \mathrm{C}\right)$.

\subsection{Physical Properties Elemental Carbon, Hydrogen and Nitrogen Analysis (CHN)}

Schiff base Ligand 1: yellow needles solid (80\%); m.p $111^{\circ} \mathrm{C}-112^{\circ} \mathrm{C}$; C (76.07) H (8.46) N (7.39); Schiff base Ligand 2: yellow needles solid $(85 \%)$; m.p $95^{\circ} \mathrm{C}-96^{\circ} \mathrm{C}$; C (74.60) H (7.27) N (9.17); Schiff base Ligand 3: yellow solid (86\%); m.p $132^{\circ} \mathrm{C}-133^{\circ} \mathrm{C}$; C (47.92) H (4.40) N (6.02); Complex 1: green solid (90\%); m.p $341^{\circ} \mathrm{C}-343^{\circ} \mathrm{C}$; C (59.29) H (6.16) N (5.41); Complex 2: orange solid (80\%); m.p $335^{\circ} \mathrm{C}-336^{\circ} \mathrm{C}$; C (55.46) H (5.02) N (6.18); Complex 3: orange solid (87\%); m.p $305^{\circ} \mathrm{C}-306^{\circ} \mathrm{C} ; \mathrm{C}(40.12) \mathrm{H}(3.45) \mathrm{N}(5.21)$.

\subsection{Fourier Transform Infrared (FTIR)}

Analysis of FTIR shows that some significant changes of the important bands can be observed from FTIR spectra of free Schiff base ligands and their complexes. The displacement of $\mathrm{C}=\mathrm{N}$ stretching frequencies from 1615 $1631 \mathrm{~cm}^{-1}$ in the free Schiff base ligands to lower values of $1606-1611 \mathrm{~cm}^{-1}$ in the complexes indicating the coordination of azomethine nitrogen to the palladium metal. This result shows that the contribution of $\mathrm{C}=\mathrm{N}$ stretching mode has been reduced as the electron pairs on a nitrogen atom is involved in bond formation with the palladium ion [4]. Besides, the broad $\mathrm{OH}$ band at $>3400$ $\mathrm{cm}^{-1}$ in the free Schiff base ligands spectrum has totally disappeared in complexes spectrum, suggesting the strong participation of the $\mathrm{OH}$ group in chelate formation to the palladium atom via the deprotonation of phenolic hydrogen [5].

Schiff base ligand 1: $3434(\mathrm{OH}) 1615(\mathrm{C}=\mathrm{N}) 1544$, $1455(\mathrm{C}=\mathrm{C}$ ar. $) \mathrm{cm}^{-1}$; Schiff base ligand 2: $3440(\mathrm{OH})$ $1631(\mathrm{C}=\mathrm{N}) 1579,1428(\mathrm{C}=\mathrm{C}$ ar. $) \mathrm{cm}^{-1}$; Schiff base ligand 3: $3446(\mathrm{OH}) 1631(\mathrm{C}=\mathrm{N}) 1570,1478(\mathrm{C}=\mathrm{C}$ ar. $)$ $\mathrm{cm}^{-1}$; Complex 1: $1606(\mathrm{C}=\mathrm{N})$ 1528, $1478(\mathrm{C}=\mathrm{C}$ ar. $)$ $\mathrm{cm}^{-1}$; Complex 2: $1611(\mathrm{C}=\mathrm{N}) 1539,1428(\mathrm{C}=\mathrm{C}$ ar. $)$ $\mathrm{cm}^{-1}$; Complex 3: $1608(\mathrm{C}=\mathrm{N})$ 1526, $1461(\mathrm{C}=\mathrm{C}$ ar. $)$ $\mathrm{cm}^{-1}$.

\subsection{Nuclear Magnetic Resonance (NMR)}

From ${ }^{1} \mathrm{H}-\mathrm{NMR}$ data, the strong participation of the $\mathrm{OH}$ group in chelation through the deprotonation of phenolic hydrogen is indicated by the disappearance of the $\mathrm{OH}$ singlet signal at very downfield chemical shift in the free Schiff base ligand spectrum [5]. Meanwhile, based on ${ }^{13} \mathrm{C}$-NMR analysis, displacement of phenolic carbon $(\mathrm{C}-\mathrm{OH})$ and azomethine carbon $(\mathrm{C}=\mathrm{N})$ from upfield in non-coordinated ligands to the downfield in the complexes suggest the deprotonation and coordination of azomethine nitrogen atom and phenolic oxygen atom to the palladium atom. Besides that, the signals from aromatic carbons in the complexes have shifted from upfield to the downfield after complexation, which further supported the FTIR data in which the ligand is coordinated to the palladium atom through the azomethine nitrogen atom and the phenolic oxygen atom.

Schiff base ligand 1: ${ }^{1} \mathrm{H}-\mathrm{NMR} 12.30(\mathrm{C}-\mathrm{OH}) 6.57-$ $7.40(\mathrm{C}-\mathrm{H}$ ar. $)$ ppm ${ }^{13} \mathrm{C}-\mathrm{NMR} 171.83(\mathrm{C}=\mathrm{N}) 164.31$ (C-OH) ppm; Schiff base ligand 2: ${ }^{1} \mathrm{H}-\mathrm{NMR} 13.60$ (C-OH) $6.88-7.37$ (C-H ar.) ppm ${ }^{13} \mathrm{C}-\mathrm{NMR} 165.71$ (C = N) $161.29(\mathrm{C}-\mathrm{OH}) \mathrm{ppm}$; Schiff base ligand 3: ${ }^{1} \mathrm{H}-\mathrm{NMR}$ $13.53(\mathrm{C}-\mathrm{OH}) 6.87$ - 7.43 (C-H ar.) ppm ${ }^{13} \mathrm{C}-\mathrm{NMR}$ $164.59(\mathrm{C}=\mathrm{N}) 160.26(\mathrm{C}-\mathrm{OH})$ ppm; Complex 1: ${ }^{1} \mathrm{H}$-NMR 6.39 - 7.26 (C-H ar.) ppm ${ }^{13} \mathrm{C}-\mathrm{NMR} 218.15$ (C = N) $167.09(\mathrm{C}-\mathrm{OH})$ ppm; Complex 2: ${ }^{1} \mathrm{H}-\mathrm{NMR} 6.49-$ 7.25 (C-H ar.) ppm ${ }^{13} \mathrm{C}-\mathrm{NMR} 162.96(\mathrm{C}=\mathrm{N}) 165.34$ (C-OH) ppm; Complex 3: ${ }^{1} \mathrm{H}-\mathrm{NMR} 6.72-7.48$ (C-H ar.) ppm ${ }^{13} \mathrm{C}-\mathrm{NMR} 163.61(\mathrm{C}=\mathrm{N}) 204.45(\mathrm{C}-\mathrm{OH}) \mathrm{ppm}$.

\subsection{X-Ray Crystallography Analysis}

Suitable crystal of Schiff base ligand 1 for X-ray analysis was obtained by slow evaporation of the ligand solution in dichloromethane and n-hexane (1:1) mixture at low temperature $\left(4^{\circ} \mathrm{C}\right)$. From analysis, the bond lengths of azomethine C8-N1, 1.295(2) $\AA$ and C15-N2, 1.286(2) $\AA$ in the molecule are consistent with normal $\mathrm{C}=\mathrm{N}$ bond lengths as observed in other similar azomethine compound [6]. Besides, there are two intramolecular strong hydrogen bonding, N1-H1A and N2-H2A which contribute to the stability of the molecule (Figure 1).

Suitable crystal of palladium (II) complex 2 for X-ray 
analysis was obtained by slow evaporation of a mixture solution of chloroform and $n$-hexane $(1: 1)$ at low temperature $\left(4^{\circ} \mathrm{C}\right)$. As shown in Figure 2, the $\mathrm{Pd}^{\mathrm{II}}$ metal centre has a cis-planar coordination by the two phenolic oxygen atoms and two imine nitrogen atoms. The Pd-O distances are in the range 1.979(3) - 2.008(4) $\AA$ with Pd-N distances 1.981(3) - 2.014(3) $\AA$, which are typical of the square-planar $\mathrm{Pd}^{\mathrm{II}}$ complex of Schiff base ligand [7]. The bond angles around $\mathrm{Pd}^{\mathrm{II}}$ ions suggested that the complex has a distorted square-planar geometry as indicated by the angles O-Pd-O in the range 79.66(11) 80.54(16), O-Pd-N in the range 92.14(13) - 92.95(11) and N-Pd-N in the range 94.92(12) - 94.95(15), deviating substantially from that expected for a regular squareplanar geometry.

\subsection{Catalytic Testing}

\subsubsection{Heck Reaction}

Palladium (II) complexes were tested in a Heck reaction between iodobenzene and methyl acrylate to produce methyl cinnamate. The general procedure is as follow: iodobenzene $(0.20 \mathrm{~g} ; \rho=1.830 ; 0.11 \mathrm{~mL} ; 1 \mathrm{mmol})$, methyl acrylate $(0.17 \mathrm{~g} ; \rho=0.955 ; 0.18 \mathrm{~mL} ; 2 \mathrm{mmol})$, base (2.4 mmol), palladium (II) Schiff base complex (1.0 mmol $\%$; $0.01 \mathrm{mmol})$ and solvent $\mathrm{N}, \mathrm{N}$-dimethylacetamide, DMA (5 mL) were mixed together in a Radley's 12placed reaction carousel and was reflux for 24 hours whilst being purged with nitrogen. (Bases: $\mathrm{Et}_{3} \mathrm{~N}, \mathrm{NaHCO}_{3}, \mathrm{Na}_{2} \mathrm{CO}_{3}$ and NaOAc; Temperature: $100^{\circ} \mathrm{C}, 120^{\circ} \mathrm{C}$ and $140^{\circ} \mathrm{C}$ ).

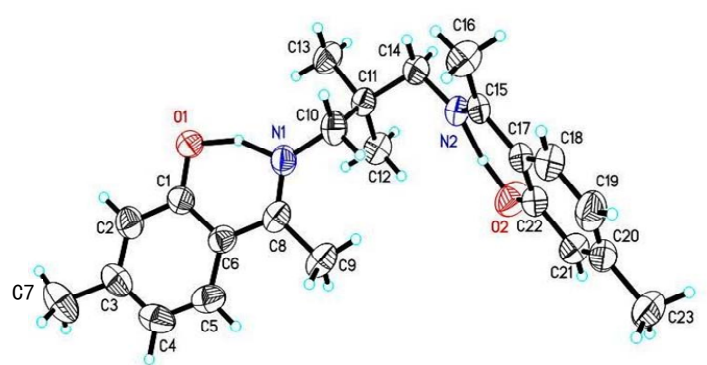

Figure 1. ORTEP plot of Schiff-base ligand 1.

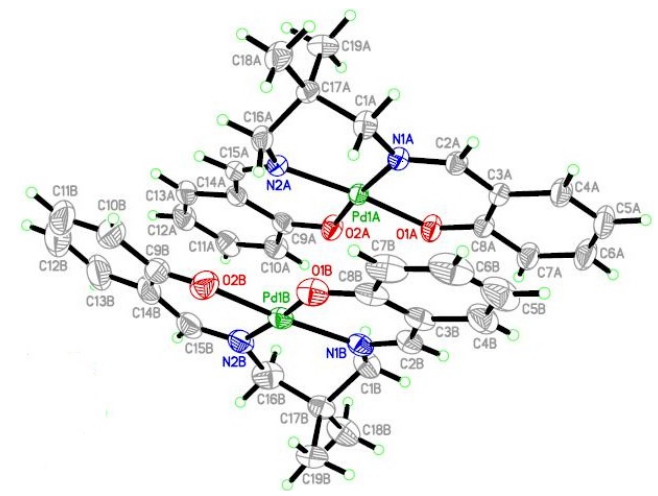

Figure 2. ORTEP plot of complex 2.

\subsubsection{Suzuki Reaction}

Palladium (II) complexes were tested in Suzuki reaction between iodobenzene and phenylboronic acid to produce biphenyl. The general procedure is as follow: iodobenzene $(0.20 \mathrm{~g} ; \rho=1.830 ; 0.11 \mathrm{~mL} ; 1 \mathrm{mmol})$, phenylboronic acid $(0.24 \mathrm{~g} ; 2 \mathrm{mmol})$, base $(2.4 \mathrm{mmol})$, palladium (II) Schiff base complex (1.0 mmol\%; 0.01 mmol) and solvent DMA ( $5 \mathrm{~mL})$ were mixed together in Radley's 12-placed reaction carousel and was reflux for 24 hours whilst being purged with nitrogen. (Bases: $\mathrm{Et}_{3} \mathrm{~N}$, $\mathrm{KF}, \mathrm{K}_{2} \mathrm{CO}_{3}$ and $\mathrm{K}_{3} \mathrm{PO}_{4}$; Temperature: $100^{\circ} \mathrm{C}, 120^{\circ} \mathrm{C}$ and $\left.140^{\circ} \mathrm{C}\right)$.

\section{Results and Discussion}

\subsection{Catalytic Heck Reaction Studies}

The synthesized palladium (II) complexes were subjected in the catalytic Heck reaction of iodobenzene and methyl acrylate by using DMA solve + nt. Catalyst loading was kept to $1.0 \mathrm{mmol} \%$, so as to give an expected TON of 100 if $100 \%$ conversion of iodobenzene was achieved.

\subsubsection{Effect of Bases}

The function of base in Heck reaction is to neutralize the acidic condition product by hydrogen halide in reductive elimination step and regeneration of catalyst to continue the catalytic cycles. In this study, four types of bases have been used; $\mathrm{Et}_{3} \mathrm{~N}, \mathrm{NaHCO}_{3}, \mathrm{Na}_{2} \mathrm{CO}_{3}$ and $\mathrm{NaOAc}$, in order to study the effect of bases towards the percentage conversion of iodobenzene. Some organic bases act as a source of hydride and promote the hydrogenation of aromatic compounds. Due to this property or effect, there is usually a competition between vinylation and hydrogenation in the Heck reaction and the selectivity pattern will be influenced by the type of base used. As reported by Kiviaho [8], selectivity for a vinylation product like methyl cinnamate is high when $\mathrm{Et}_{3} \mathrm{~N}$ is the base used in the reactions which correspond to our studies in which $\mathrm{Et}_{3} \mathrm{~N}$ gives $100 \%$ conversion of iodobenzene with complex 1 and more than $90 \%$ conversion with the other two complexes. In contrast, the low conversion achieved for $\mathrm{NaHCO}_{3}$ is probably due to the insolubility of $\mathrm{NaHCO}_{3}$ in the organic solvent used.

\subsubsection{Effect of Temperature}

Reaction temperature assists in the activation of the iodobenzene which usually occurs at reaction temperature more than $100^{\circ} \mathrm{C}$. However, the reaction temperature must be carefully controlled to avoid the formation of palladium black which will inhibit the catalytic cycle if the temperature is too high. In order to study the effect of temperature on the conversion of iodobenzene, the catalytic reaction temperatures were varied at $100^{\circ} \mathrm{C}, 120^{\circ} \mathrm{C}$ and $140^{\circ} \mathrm{C}$ using $\mathrm{Et}_{3} \mathrm{~N}$ as base. From the results, it 
showed that the best reaction temperature was found to be $140^{\circ} \mathrm{C}$, which all the complexes gave $100 \%$ conversion. Among all of the three complexes, complex 1 still maintained with the highest conversion even at lower temperature than $120^{\circ} \mathrm{C}$. The higher activities of this complex may be explained in terms of ligand effect. The bulkier and more electron-rich ligand is thought to accelerate the oxidative addition of aryl halides and reductive elimination steps, so that the catalyst regeneration in catalytic cycles is faster [9]. However from our observation, the Heck reaction using temperature greater than $140^{\circ} \mathrm{C}$ was avoided due to the formation of palladium black, which therefore terminated the catalytic cycle.

\subsection{Catalytic Suzuki Reaction Studies}

The synthesized palladium (II) complexes were subjected in the catalytic Suzuki reaction of iodobenzene and phenylboronic acid by using DMA solvent. Catalyst loading was kept to $1.0 \mathrm{mmol} \%$, so as to give an expected TON of 100 if $100 \%$ conversion of iodobenzene was achieved.

\subsubsection{Effect of Bases}

In this study, four types of bases have been used; $\mathrm{Et}_{3} \mathrm{~N}$, $\mathrm{KF}, \mathrm{K}_{2} \mathrm{CO}_{3}$ and $\mathrm{K}_{3} \mathrm{PO}_{4}$, in order to study the effect of bases towards the percentage conversion of iodobenzene. The type of bases was chosen based on their performance in Suzuki reaction to form similar biphenyl products $[10,11]$. In Suzuki reaction, the presence of base is needed since the cross coupling via transmetallation step is difficult due to the low nucleophilicity of organic groups (R) on the boron atom. The role of the base is explained by activation of palladium (II) complex or boranes. According to Kotha [12], the base is involved in the coordination sphere of the palladium to activate the palladium catalyst by formation of intermediate (alkoxo) palladium species which is known to accelerate the transmetallation step. Besides, the nucleophilicity of organic groups is enhanced by quaternization of the boron with bases which facilitates transmetallation. From our observation, the $\mathrm{Et}_{3} \mathrm{~N}$ is the most favourable one compared to other bases. Most probably, the $\mathrm{Et}_{3} \mathrm{~N}$ mixed well with the reaction mixture since it exists in liquid form and easily interferes in coordination sphere of palladium complex.

\subsubsection{Effect of Temperature}

In order to study the effect of temperature on the conversion of iodobenzene, the catalytic reaction temperatures were varied at $100^{\circ} \mathrm{C}, 120^{\circ} \mathrm{C}$ and $140^{\circ} \mathrm{C}$ with $\mathrm{Et}_{3} \mathrm{~N}$ as base. From the results, it showed that the best reaction temperature was found to be $140^{\circ} \mathrm{C}$, where $100 \%$ conversion was achieved after 24 hours reaction by using complex 1. Among three complexes, the complex 2 was the worst performer with only giving $5 \%$ conversion com- pared to $46 \%$ conversion with complex 1 at $100^{\circ} \mathrm{C}$ reaction temperature. This can be explained by the presence of the methyl group on the carbon of the azomethine group of complex 1which dramatically increases the rate of reaction. This may be due to the electronic effect of a methyl group, which ultimately increases the electronic environment around the palladium centre [13]. The electronic properties on palladium centre facilitate the interruption of palladium catalyst in aryl or vinyl halides bonding in the oxidative addition steps on the catalytic cycles and ultimately increasing the rate of reaction.

\section{Conclusion}

In this research, three palladium (II) Schiff base complexes have been successfully synthesized and characterized. Based on the elemental CHN analysis, FTIR, $1 \mathrm{H}$, 13C-NMR spectral studies and X-ray crystallographic analysis, we suggest that the Schiff base ligands acted as $\mathrm{N}, \mathrm{N}, \mathrm{O}, \mathrm{O}-$ tetradentate ligand and have bonded to the palladium atom through the azomethine nitrogen atom $(\mathrm{C}=$ $\mathrm{N})$ and the phenolic oxygen atom. These complexes were then subjected in catalytic Heck and Suzuki reaction of iodobenzene. The results showed that the complex 1 gives conversion up to $100 \%$ using triethylamine as base at temperature $120^{\circ} \mathrm{C}-140^{\circ} \mathrm{C}$ for both Heck and Suzuki reaction of iodobenzene. The higher activities of the complex 1 maybe can be explained in term of ligand effect. The oxidative addition is well known as the rate determining step in cross coupling reaction, thus, electron-rich ligands are usually needed to make the palladium metal easily oxidized. The presence of the methyl group on the carbon azomethine $(\mathrm{C}=\mathrm{N})$ increased the electronic environment around the palladium centre which ultimately, accelerates the oxidative addition of aryl halides and reductive elimination steps.

\section{Acknowledgements}

The research is financed by Ministry of Science Technology and Innovation (MOSTI) for the Science Fund 03-01-06-SF0273).

\section{REFERENCES}

[1] M. Wang, H. Zhu, K. Jin, D. Dai and L. Sun, "Ethylene Oligomerization by Salen-Type Zirconium Complexes to Low-Carbon Linear $\alpha$-Olefins," Journal of Catalysis, Vol. 220, No. 2, 2003, pp. 392-398.

[2] F. Marchetti, C. Pettinari, R. Pettinari, A. Cingolani, D. Leonesiand and A. Lorenzotti, "Group 12 Metal Complexes of Tetradentate $\mathrm{N}_{2} \mathrm{O}_{2}$-Schiff-Base Ligands Incorporating Pyrazole Synthesis, Characterization and Reactivity toward S-Donors, N-Donors, Copper and Tin Acceptors," Polyhedron, Vol. 18, No. 23, 1999, pp. 30413050. doi:10.1016/S0277-5387(99)00230-2

[3] T. Hokelek, Z. Kilic, M. Isiklanand and M. Toy, "Intra- 
molecular Hydrogen Bonding and Tautomerism in Schiff Bases. Part II. Structures of 1-[N-(2-Pyridyl) Aminomethylidene $-2(1 \mathrm{H})-N a p h t a l e n o n e ~(1)$ and bis[2-Hydroxy$\kappa O-N$-(2-Pyridyl)-1-Naphthaldiminato- $\kappa N]$ Zinc(II)(2)," Journal of Molecular Structure, Vol. 523, No. 1-3, 2000, pp. 61-69. doi:10.1016/S0022-2860(99)00376-2

[4] E. T. G. Cavalheiro, F. C. D. Lemos, J. Z. Schpector and E. R. Dockal, "The Thermal Behaviour of Nickel, Copper and Zinc Complexes with the Schiff Bases cis- and transN,N'-Bis(Salicylidene)-1,2-Ciclohexadiamine (Salcn)," Thermochimica Acta, Vol. 370, No. 1-2, 2001, pp. 129-133.

[5] A. A. Soliman and W. Linert, "Investigation on New Transition Metal Chelates of 3-Methoxy-Salicylidene-2-Aminothiphenol Schiff Base," Thermochimica acta, Vol. 338, No. 1-2, 1999, pp. 67-75. doi:10.1016/S0040-6031(99)00201-4

[6] M. Shamsuddin, A. M. M. Nur and B. M. Yamin, "N-[2(Diphenylphosphanyl) benzylidene]-4-methylaniline," Acta Crystallographica, Vol. E61, No. 7, 2005, pp. o2263o2264.

[7] R. A. Adrian, G. A. Broker, E. R. T. Tiekink and J. A. Walmsley, "Palladium (II) Complexes of 1,10-Phenanthroline: Synthesis and X-Ray Crystal Structure Determination," Inorganica Chimica Acta, Vol. 361, No. 5, 2008, pp. 1261-1266. doi:10.1016/j.ica.2007.08.019

[8] J. Kiviaho, T. Hanaoka, Y. Kubotaand and Y. Sugi, "Heterogeneous Palladium Catalysts for Heck Reaction," Journal of Molecular Catalysis A: Chemical, Vol. 101, No. 1, 1995, pp. 25-31.
[9] D. E. De Vos, M. Dams, B. F. Sels and P. A. Jacobs, "Ordered Mesoporous and Microporous Molecular Sieves Functionalized with Transition Metal Complexes as Catalysts for Selective Organic Transformations," Chemical Reviews,Vol. 102, No. 10, 2002, pp. 3615-3640. doi:10.1021/cr010368u

[10] N. T. S. Phan, D. H. Brown and P. Styring, "A PolymerSupported Salen-Type Palladium Complex as a Catalyst for the Suzuki-Miyaura Cross-Coupling Reaction," Tetrahedron Letters, Vol. 45, No. 42, 2004, pp. 7915-7919. doi:10.1016/i.tetlet.2004.08.153

[11] N. M. Chaignon, I. J. S. Fairlamb, A. R. Kapdi, R. J. K. Taylorand and A. C. Whitwood, "Bis(triphenylphosphine) Palladium (II) Phthalimide-An Easily Prepared Precatalyst for Efficient Suzuki-Miyaura Coupling of Aryl Bromides," Journal of Molecular Catalysis A: Chemical, Vol. 219, No. 2, 2004, pp. 191-199. doi:10.1016/j.molcata.2004.05.008

[12] S. Kotha, K. Lahiriand and D. Kashinath, "Recent Applications of the Suzuki-Miyaura Cross-Coupling Reaction in Organic Synthesis," Tetrahedron, Vol. 58, No. 48, 2002, pp. 9633-9695. doi:10.1016/S0040-4020(02)01188-2

[13] S. Paul and J. H. Clark, "Structure-Activity Relationship between Some Novel Silica Supported Palladium Catalysts: A Study of the Suzuki Reaction," Journal of Molecular Catalysis A: Chemical, Vol. 215, No. 1-2, 2004, pp. 107-111. doi:10.1016/j.molcata.2003.12.034 